\title{
Is the Response to Growth Hormone in Short Children Born Small for Gestational Age Dependent on Genetic or Maternal Factors?
}

\author{
O. Mehls $^{a} \quad$ A. Lindberg ${ }^{c} \quad$ M. Bettendorf ${ }^{b} \quad$ H.-G. Doerr ${ }^{d} \quad$ B.P. Hauffa ${ }^{\text {e }}$ S. Kaspers ${ }^{f}$ \\ T. Rohrerg N.Stahnke ${ }^{h}$ M.B. Ranke ${ }^{i}$ on behalf of the German KIGS Board \\ Divisions of a Paediatric Nephrology and ${ }^{b}$ Paediatric Endocrinology, University Hospital for Children and \\ Adolescents, Heidelberg, Germany; ' $P$ Pfizer Endocrine Care, KIGS/KIMS/ACROSTUDY Medical Outcomes, Stockholm, \\ Sweden; ${ }^{d}$ Division of Paediatric Endocrinology, University Hospital for Children and Adolescents, Erlangen, \\ eDepartment of Paediatric, Endocrinology and Diabetes, University Hospital for Children and Adolescents,

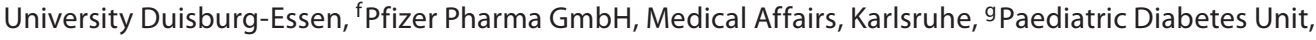 \\ Department of Paediatric and Adolescent Medicine, Saarland University Hospital, Homburg/Saar, \\ hPaediatric Endocrinology, Endokrinologikum, Hamburg, and 'Department of Paediatrics and Endocrinology, \\ University Children's Hospital, Tübingen, Germany
}

\section{Key Words}

Growth hormone treatment - Small for gestational age •

Silver-Russell syndrome $\cdot$ Smoking $\cdot$ Heart defects •

Infections

\begin{abstract}
Background/Aims: We investigated whether genetic or maternal/environmental risk factors for being born small for gestational age (SGA), e.g. Silver-Russell syndrome, congenital heart defects, infections of mothers or smoking during pregnancy, explain the variation in the first-year growth response to GH therapy. Methods: Secondary analysis was made of growth response in 135 short prepubertal German children (66\% males) enrolled in a SGA phase III trial. Initial mean patient age was $6.8 \pm 2.6$ years; mean patient height SDS $-3.8 \pm 1.2$, and GH treatment dose was $0.066 \mathrm{mg} / \mathrm{kg}$ body weight per day. Results: Growth velocity increased by $4.5 \pm 2.0 \mathrm{~cm} /$ year and height SDS by $1.0 \pm 0.5$ SDS. Although patient number was limited and variation was high, both growth response $(\mathrm{cm} /$ year) and change in height SDS did not appear to differ between subgroups which also did not
\end{abstract}

\section{KARGER}

Fax +4161306 1234

E-Mail karger@karger.ch

www.karger.com (c) 2009 S. Karger AG, Basel

0301-0163/09/0722-0106\$26.00/0

Accessible online at:

www.karger.com/hre differ in terms of Studentized residuals set up in the KIGS growth prediction model for SGA. Likewise, in a step-forward multivariate analysis, the variables Silver-Russell syndrome, congenital heart defects, infections of mothers and smoking were not identified as independent factors influencing growth velocity. Conclusion: The retrospectively analyzed genetic and maternal/environmental risk factors for SGA do not appear to explain the observed patient variance in response to $\mathrm{GH}$. Larger prospective studies are needed, however, to substantiate these preliminary findings.

Copyright $\odot 2009$ S. Karger AG, Basel

\section{Introduction}

The term, small for gestational age (SGA), is used to describe fetuses or newborn infants whose weight and/or length is less than expected for their gestational age and gender $[1,2]$. The term SGA has been used as birth weight

The study was sponsored by Pfizer Pharma GmbH, Germany. 
or length of less than -2 SD or less than the 10th or 3rd centiles for gestational age as a cutoff point. A cutoff of less than -2 SD is now recommended because this will identify the majority in whom ongoing growth assessment is required [3]. A new definition of SGA is based on fetal growth potential [4]. Children born SGA reach an adult height approximately 1 SD below the mean. Most SGA infants achieve sufficient postnatal catch-up growth to normalize their stature by 2 years of age $[5,6]$. Some preterm infants may take more years to achieve height in the normal range [7]. Nevertheless, a remarkable number of children do not show sufficient catch-up growth and remain stunted. Many authors showed that treatment of those children with recombinant human growth hormone (rhGH) resulted in an increase in mean growth velocity [8] and final height [9]. However, the response to GH treatment varied widely between individual patients $[10,11]$.

SGA is a descriptive rather than a diagnostic term for a very heterogeneous group with influences from maternal, placental, fetal, genetic and environmental factors $[2$, 12]. Calorie restriction and subnormal maternal weight gain might result in reduced birth weight [13], placental growth is correlated with birth weight but not with length [14], and smoking during pregnancy is correlated to birth weight, length and head circumference [15]. Gene abnormalities identified in isolated or syndromal growth disorders can influence fetal growth and postnatal catch-up [16]. Imprinted genes have an important effect on fetoplacental development $[17,18]$. Abnormalities of genes imprinted within the $11 \mathrm{p} 15$ region are frequently found in Silver-Russell syndrome (SRS) [19,20] which exhibits SGA and number of other characteristic clinical features $[21,22]$.

It is not known if or to what extent the factors which potentially influence fetal growth also influence the response to growth hormone treatment in short children born SGA. A four parameter prediction model (age at start, weight SDS at start, GH dose and mid-parental height SDS) could explain 52\% of the variability of growth following GH treatment [23]. Analyzing determinants related to height SDS at onset of puberty or to adult height SDS, gender and IGFBP-3 SDS at start of GH treatment were identified as additional predictors by de Ridder et al. [24].

In the present study, we hypothesized that genetic or maternal/environmental risk factors, e.g. SRS, congenital heart defects (CHD), regular smoking (SM) or serious infections of the mothers (IM) during pregnancy, might modify the patient response to $\mathrm{GH}$. We compared the growth response to $\mathrm{GH}$ in patients born SGA, with or without the above-mentioned potential risk factors, by performing a retrospective secondary analysis in the intention-to-treat (ITT) population of a German phase-III study conducted between January 1994 and March 1998 [25].

\section{Patients and Methods}

\section{Study Design}

In 1994, a multicenter trial evaluating the efficacy and safety of $\mathrm{GH}$ (Genotropin ${ }^{\circledR}$ ) in children born short for gestational age was started [25]. In the one-arm, uncontrolled, open-labeled, non-comparative, multicenter study, 135 short prepubertal children born SGA were treated with subcutaneous injections of somatropin in a mean dosage of $0.066 \mathrm{mg} / \mathrm{kg}$ body weight per day for 2 years.

The following inclusion criteria were used: (1) male and female patients $>2$ years of age; (2) prepubertal at start of therapy (breast stage $=1$, testis volume $<4 \mathrm{ml}$ based on Tanner criteria); (3) height SDS below -2 SD for chronological age [26]; (4) height velocity SDS $<0$ SD for chronological age [26], based on a $12 \pm 3$ month observation period before screening; (5) birth weight and/or birth length below $-2.0 \mathrm{SD}$ for gestational age [26]; (6) GH level $>10 \mathrm{ng} /$ $\mathrm{ml}(>20 \mathrm{mU} / \mathrm{l})$ during any provocation test (except GHRH test), and (7) signed written informed consent obtained from the patients' parents/guardian.

Exclusion criteria were: (1) other endocrine diseases except for well-substituted hypothyroidism; (2) severe chronic disease which might influence linear growth; (3) children with previous or current malignant disease; (4) chromosomal aberrations or syndromes, e.g. Ullrich-Turner syndrome, for girls a chromosomal analysis was obligatory, however children with SRS and intrauterine growth retardation due to drug usage (smoking and/or alcohol) were included; (5) children with clinical and/or radiographic signs of skeletal dysplasia; (6) strong suspicion of psychosocial short stature, and (7) children participating in other clinical trials.

150 patients were included, 138 of them were treated with GH, whereas 12 patients were not treated with the study medication and were therefore excluded from analysis.

The ITT analysis included all patients $(n=135)$ for whom data on the primary efficacy variable were available regardless of any protocol deviations.

For all patients, data for age, sex, height ( $\mathrm{cm}$ and height SDS) at start of GH therapy and 1 year prior to therapy were collected. Other data on body length, body weight and head circumference at birth as well as the modus of delivery were collected. The heights of the father and mother were documented. Furthermore, data for intrauterine risk factors (serious IMs, regular (daily) SM (the number of cigarettes per day was not recorded) as well as potential genetic risk factors, SRS, or the presence of CHD) were documented. No systematic genotyping for SRS was performed. The documented serious IMs included toxoplasmosis $(n=1)$, cytomegalovirus infection $(\mathrm{n}=1)$, amniotic infection $(\mathrm{n}=1)$, genital thrush infection $(n=1)$, febrile enteritis $(n=1)$, febrile infection $(\mathrm{n}=2)$, and pyelonephritis $(\mathrm{n}=1)$. 
Table 1. Characteristics of all patients at birth and at start of GH treatment

\begin{tabular}{|c|c|c|c|c|c|c|c|}
\hline & All patients & $\begin{array}{l}\text { Silver-Russell } \\
\text { syndrome }\end{array}$ & $\begin{array}{l}\text { Congenital } \\
\text { heart defect }\end{array}$ & $\begin{array}{l}\text { Smoking of } \\
\text { mother }\end{array}$ & $\begin{array}{l}\text { Serious infection } \\
\text { of mother }\end{array}$ & Other & $\mathrm{p}^{*}$ \\
\hline Number & 135 & 24 & 6 & 21 & 8 & 76 & \\
\hline Weight at birth, kg & $1.95 \pm 0.58$ & $1.87 \pm 0.64$ & $1.88 \pm 0.57$ & $1.61 \pm 0.64$ & $1.85 \pm 0.50$ & $2.02 \pm 0.58$ & \\
\hline Length at birth, $\mathrm{cm}$ & $42.7 \pm 4.4$ & $41.7 \pm 5.1$ & $42.3 \pm 4.9$ & $39.8 \pm 5.5$ & $42.4 \pm 4.4$ & $43.3 \pm 3.9$ & \\
\hline Age at start, years & $6.8 \pm 2.6$ & $6.0 \pm 2.5$ & $4.5 \pm 2.1$ & $7.3 \pm 2.8$ & $7.6 \pm 3.6$ & $7.1 \pm 2.5$ & $<0.05$ \\
\hline
\end{tabular}

* Kruskal-Wallis test.

The 135 patients available for the primary ITT analysis [25] were also used for the present secondary analysis.

The patients were retrospectively grouped according to the following risk factors: SRS $(n=24)$, CHD $(n=6)$, SM $(n=21)$ and IM $(n=8)$. If a patient showed characteristics for two of the subgroups, he was classified into only one group in the above sequence. The growth responses of these patient groups were compared to each other and to the response in those patients without the four potential risk factors, e.g. the rest of the total cohort ( $\mathrm{n}=$ 76).

The growth response was determined by the increase in height velocity $(\mathrm{cm})$, compared to the growth velocity during the year prior to GH treatment and by the change in height SDS within the first treatment year. The height SDS was calculated according to Brandt and Reinken [26]. SDS values indicate the deviation in the patient's height from the average height of healthy children dependent on age and sex, expressed by standard deviation units which is calculated by the following formula:

[Patient's height - mean height (age, sex)]/Standard deviation (age, sex) for mean.

\section{Analysis Strategy and Statistics}

The growth response in patients classified as SRS, CHD, IM and SM was compared to that in patients born SGA without the mentioned potential risk factors. The pretreatment height velocity (cm/year) and height SDS were compared to height velocity and height SDS measured after 1 and 2 years (months 12 and 24). Group differences were analyzed by the Kruskal-Wallis test.

Using the KIGS prediction model for growth response to $\mathrm{GH}$ in short prepubertal children born SGA [23], we tested whether the observed height velocity ( $\mathrm{cm} /$ year) during the first treatment year for the various subgroups differed from each other and/or from the predicted height velocity calculated for a large KIGS SGA population. The KIGS prediction model uses age at start (years), weight SDS at start, GH dose $(\mathrm{mg} / \mathrm{kg} \times$ day) and mid-parental height SD score as variables for predicting the first-year response $(\mathrm{cm} /$ year) in prepubertal children born SGA [23].

In order to identify additional predictors to those tested in the KIGS prediction model, group comparisons (Wilcoxon test, Fischer exact test), univariate linear regression analyses and stepforward multivariate analyses were performed to identify whether height velocity ( $\mathrm{cm} /$ year) or the increase in height velocity
( $\Delta$ height velocity $=$ height velocity first treatment year $(\mathrm{cm})-$ height velocity during the pretreatment year), or the increase in height SDS ( $\Delta$ height SDS = height SDS after 1 year - height SDS at start) was significantly influenced by the following variables: sex, age, weight, weight SDS, height, height SDS at start; the target height, and subgroup identity (SRS, CHD, IM, SM).

\section{Results}

The children of the study population were typical for short children born SGA. The mean duration of pregnancy was $37.6 \pm 3.3$ weeks. Mean weight at birth for the total study population was less than $2 \mathrm{~kg}$ and mean length about $43 \mathrm{~cm}$ (table 1). The children had failed to achieve spontaneous catch-up growth and started $\mathrm{GH}$ treatment at a mean age of 6.8 years. At the start of $\mathrm{GH}$ treatment the mean height SDS of all 135 patients amounted to -3.8 \pm 1.2. The age at GH start significantly differed for the subgroups, being lowest in children with CHD and SRS. Although younger, height SDS at the start of GH treatment in these groups was more reduced than in the other patients.

The growth response to GH treatment did not appear to differ between subgroups (table 2). The absolute increase in height velocity above baseline was not significantly different. The obtained height velocity during the first year of treatment was about $10 \mathrm{~cm} /$ year, and did not differ between any subgroups. In the total study population of 135 patients, the mean cumulative increase in height SDS was $1.0 \pm 0.5$ during the first year, without significant differences within the subgroups. Significant differences in these parameters were also not observed during the second year of treatment. 
Table 2. Growth response to GH treatment during first and second treatment year

$\begin{array}{lllllll}\text { All patients } & \begin{array}{l}\text { Silver Russell } \\ \text { syndrome }\end{array} & \begin{array}{l}\text { Congenital } \\ \text { heart defect }\end{array} & \begin{array}{l}\text { Smoking of } \\ \text { mother }\end{array} & \begin{array}{l}\text { Serious } \\ \text { infection } \\ \text { of mother }\end{array} & \text { Others } & \mathrm{p}^{*} \\ 10.0 \pm 1.85 & 10.3 \pm 1.94 & 10.1 \pm 1.66 & 9.7 \pm 1.57 & 9.7 \pm 1.72 & 9.9 \pm 1.98 & \text { n.s. } \\ 4.54 \pm 1.99 & 4.16 \pm 2.02 & 4.02 \pm 1.62 & 4.72 \pm 1.97 & 5.99 \pm 1.58 & 4.55 \pm 1.81 & \text { n.s. } \\ & & & & & & \\ 2.43 \pm 1.75 & 2.18 \pm 2.06 & 1.57 \pm 1.62 & 2.37 \pm 1.68 & 3.54 \pm 1.80 & 2.48 \pm 1.83 & \text { n.s. } \\ 1.03 \pm 0.56 & 1.12 \pm 0.7 & 1.28 \pm 0.19 & 0.98 \pm 0.59 & 0.98 \pm 0.73 & 1.07 \pm 0.54 & \text { n.s. } \\ 1.55 \pm 0.67 & 1.78 \pm 0.8 & 1.50 \pm 0.58 & 1.50 \pm 0.54 & 1.56 \pm 0.59 & 1.59 \pm 0.62 & \text { n.s. }\end{array}$

Height velocity, $\mathrm{cm} / 1$ st year

$\Delta$ Height velocity (height velocity $1^{\text {st }}$ year

- height velocity pretreatment year), $\mathrm{cm}$

$\Delta$ Height velocity (height velocity $2^{\text {nd }}$ year

- height velocity pretreatment year), $\mathrm{cm}$

Height response ( $\Delta$ height - SDS $1^{\text {st }}$ year)

Height response ( $\Delta$ height - SDS per 2 years) $1.55 \pm 0.67$

* Kruskal-Wallis test. n.s. $=$ Not significant.

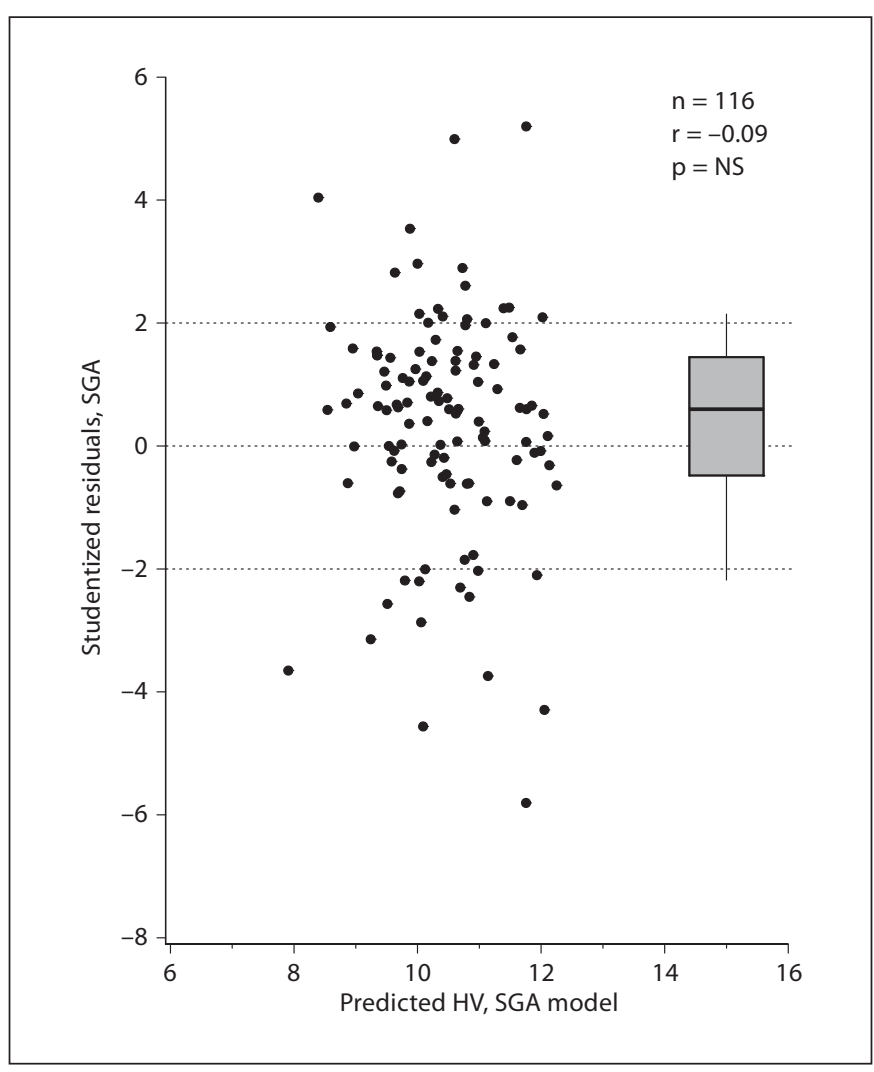

Fig. 1. Studentized residuals versus predicted height velocity (HV) during first year of GH treatment in the 135 investigated patients born SGA. The mean Studentized residual value differed slightly from zero indicating a small positive difference between the $\mathrm{GH}$ response in the children used for the prediction model $(n=24)$ and in the investigated patients.

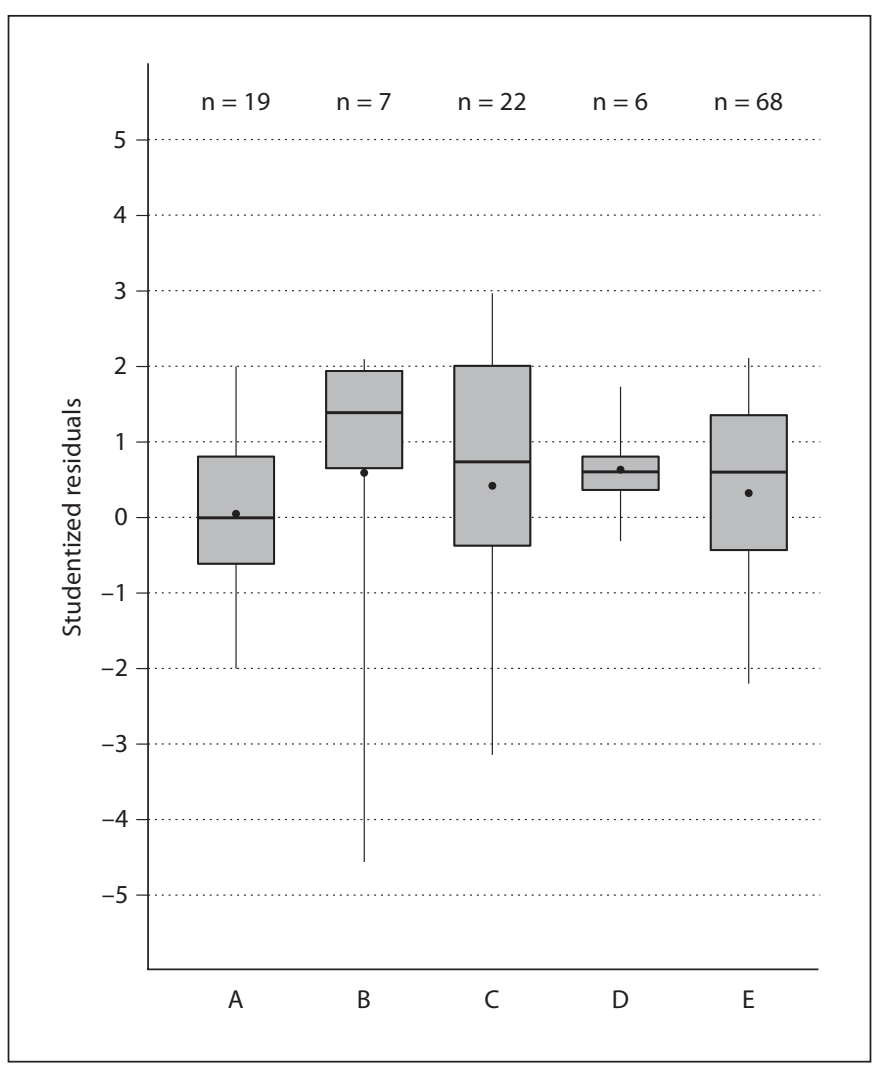

Fig. 2. Studentized residuals versus predicted height velocity in the children of the various investigated subgroups. The mean Studentized residuals of the subgroups did not differ significantly from each other $(p>0.05)$, indicating that there was no significant difference in response to $\mathrm{GH}$ during the first treatment year. The mean, median, lower and upper quartiles, and range of response to $\mathrm{GH}$ for each group are shown by the box plots. $\mathrm{A}=$ Smoking of mothers; $\mathrm{B}=$ infection of mothers; $\mathrm{C}=$ Silver-Russell syndrome; $\mathrm{D}=$ congenital heart defect; $\mathrm{E}=$ others (not $\mathrm{A}-\mathrm{D})$. 
The observed mean height velocity differed slightly from the predicted height velocity according to the KIGS prediction model. Figure 1 demonstrates the difference between predicted and observed responses (Studentized residuals). The mean observed response was significantly different from the Studentized residuals of the reference group (Studentized residual +0.3 ). Also, the variation in observed responses was slightly higher than for the KIGS population. However, the difference between the predicted and the observed response (e.g. Studentized residual) was not significantly different between any subgroups (fig. 2).

The third approach was to test whether the subgroups might respond differently to $\mathrm{GH}$ in uni- and multivariate analyses. Firstly, univariate linear regression analyses or group differences were tested for growth velocity $(\mathrm{cm} /$ year). When the parameters with the strongest univariate correlation were tested in a step-forward multivariate analysis, only the correlation with age and gender remained significant. Addition of the variables SRS, CHD, SM or IM did not increase the $\mathrm{R}^{2}$.

\section{Discussion}

The present study confirms that GH treatment is able to significantly improve growth velocity and height SDS in short children born SGA during the first two years of treatment. Our results also suggest that several genetic factors (SRS, presence of CHDs) and maternal/environmental risk factors for SGA during pregnancy (regular $\mathrm{SM}$, serious IMs during pregnancy) do not affect the responsiveness to rhGH later in life.

Because children born SGA represent a heterogeneous patient group, it is logical to assume that diverse genetic and environmental/maternal factors determine intrauterine growth. It remains unclear, however, whether these factors also modify the response to exogenous $\mathrm{GH}$ later in life. The majority of children born SGA experience catch-up growth by 2 years of age. In about $10 \%$ of these children, however, catch-up does not occur, and substandard adult height is seen when GH treatment is not begun $[5,6]$. Several attempts have been started to identify subgroups associated with specific growth patterns. Children with subnormal length, weight and head circumference at birth are born with the lowest gestational age and are shorter than children with only reduced length and weight or only length [27]. During the first 3 years, the spontaneous increase in height SDS was greater in the first group, but head circumference re- mained smaller [27]. At a mean age of 6.8 years, height SDS of all groups was nearly -3 . At this age, identical to that of the patients in the present study, the response to $\mathrm{GH}$ during the first treatment year did not differ within the 3 groups. The investigators concluded that gestational age, as well as anthropometric measurements at birth, influence the early pattern of growth, but not the response to GH at mid-childhood. Likewise, the GH receptor $\mathrm{d} 3$ polymorphism might influence prenatal growth [28], but not the growth response to GH in short SGA children later in life [29].

In the present study, birth weight and length were not significantly different between the 5 subgroups. In contrast, age and height at the start of $\mathrm{GH}$ treatment were lowest in the SRS and CHD groups. The latter is most likely explained by the greater height deficit seen in these patient groups, which was noticed earlier by parents and/ or physicians. According to the investigations of Ester et al. [27], it is unlikely that individual differences in gestational age influence the response to $\mathrm{GH}$, whereas age at the start of GH therapy was negatively correlated with the change in height SDS. This correlation was noticed in nearly all GH treatment studies in short children of various origins, and may represent a physiological principle for $\mathrm{GH}$-induced catch-up growth.

When the observed height velocity of the entire study population was compared to the predicted height velocity using the KIGS prediction model, a slight difference was found. The mean Studentized residual value was not zero (fig. 1). This might be explained by differences between the KIGS [23] and present study populations. First, the KIGS population mainly represents patients born SGA who received GH in a large pharmaco-epidemiological survey (two thirds), whereas all our patients participated in an ITT study. Furthermore, the maximum $\mathrm{GH}$ response to $\mathrm{GH}$ stimulation tests may have been lower than $10 \mathrm{mg} / \mathrm{ml}$ in the KIGS SGA population, while the present study population has consistently tested GH sufficient. In the KIGS population, initial mean patient age was 6.4 years, and mean height SDS was -2.7 . These patients received $0.04 \pm 0.02 \mathrm{mg} / \mathrm{kg} \times$ day GH. Patients in the present study did not differ from those children regarding their age at the start, but had a height SDS of -3.8, and all patients received a high dose of GH treatment $(0.066 \mathrm{mg} / \mathrm{kg} \times$ day). Patients with SRS were included in both SGA populations. The mean increase in height SDS during the first year was 0.7 in the KIGS population and 1.0 in our study population.

The small differences between the KIGS and our study populations did not appear to influence the main results 
of this study (e.g. the testing for group differences). If one of the tested subgroups possessed a lower or higher response rate to $\mathrm{GH}$ treatment, then a difference between observed and predicted growth velocities would presumably have been detected for this subgroup; however, no significant differences were found (fig. 2). Although these results were supported by the negative results of the multivariate analysis, the number of patients within each subgroup was small, and the variation (range) was wide. As a result, small differences might have been missed. It is remarkable that the 24 patients grouped as SRS did not differ from the others.

It is justified to classify SRS as a separate group [30] because of the very low birth weight, the typical clinical signs [31] and the frequently noted abnormalities of imprinted genes [32, 33]. Nevertheless, SRS patients have been uniformly included in nearly all study populations of patients born SGA. No difference in short- and longterm response to $\mathrm{GH}$ has been noted in patients followed in the Pfizer International Growth Database KIGS [16, 30]. As in the present study, height SDS at the start of treatment was lower in SRS, but the change in height SDS was similar in both groups resulting in a lower final height in SRS [16]. It remains to be shown whether genetic testing of SRS patients will improve the interpretation of study results.

Children born preterm have more than twice as many congenital cardiovascular malformations than infants born term, and 1 of 6 infants with CHD is born preterm $[34,35]$. The most frequent heart malformations seen in infants born preterm are complex or isolated ventricular septal defects, coarctation of the aorta, tetralogy of Fallot, and pulmonary valve stenosis $[35,36]$. The mechanism which might explain preterm birth and low birth weight is not known, as isolated heart defects should theoretically become functionally relevant only after birth. In the present study, only the presence of CHD, but unfortunately not the type of defect, was recorded. Also, no information was available as to whether operative corrections had been performed. Therefore, we cannot be sure whether growth retardation in this group, in which the children were relatively shorter than patients in the other subgroups, was environmental in nature. We tested this subgroup because SHD might be part of a syndromal disorder, or associated with as yet unknown genetic defects [37], which might interfere with growth. For example, several genetic defects like the 22 q11 [38] or deletion of 7q [39] have only recently been identified. It seems of practical interest to note that in the present study the severely growth-retarded patients with $\mathrm{CHD}$ showed the same response to $\mathrm{GH}$ as all other patients born SGA.

Smoking is one factor predicting placental weight and ante- and postnatal growth $[40,41]$. Even passive smoking influences birth weight [42]. The mean birth weight of newborns of SMs is about 50-150 g lower than that of non-SMs. Moreover, the risk of low birth weight $<2.5 \mathrm{~kg}$, growth restriction and premature birth is increased [43, 44]. In the present study, the exact number of cigarettes per day was not recorded but only the term 'regular = daily'. Consequently, it remains unclear whether SGA in all 21 patients of this group was simply a consequence of smoking. Both regular smoking and drinking alcohol were recorded for 3 patients. Regular alcohol consumption was recorded for another 3 non-SMs. When all 6 children from drinking mothers were grouped together, the $\mathrm{GH}$ response did not appear to be less than that seen in the other groups (data not shown). Although preliminary, these findings do not argue for an increased resistance to GH.

The host defense mechanisms against infections of the mother and fetus are only partially understood. Infection of some viruses like varicella, measles, cytomegalovirus or herpes may play a role in the pathogenesis of fetal organ damage and growth restriction $[45,46]$. Generally, subclinical ascending infections through the lower female genital tract may induce fetal sepsis and intrauterine growth retardation $[47,48]$. Periodontal infections are further possible risk factors for preterm low birth weight $[49,50]$. Unfortunately, little is known about the consequences of uncharacterized, most likely viral, febrile infections. It remains unclear whether the serious IMs listed under Patients and Methods promoted the occurrence of SGA. In addition, not all observed febrile infections might lead to the same consequences. Remarkably, the lowest response to $\mathrm{GH}$ in our study was observed in the child of a mother suffering from toxoplasmotic infection.

In conclusion, 6-year-old short children born SGA respond well to GH treatment. Interestingly, our retrospective subgroup analysis does not support the hypothesis that SRS, CHD, infections or nicotine abuse of mothers during pregnancy influence patient response to GH therapy. This conclusion is, however, only tentative because our analysis was retrospective, the number of patients in subgroups was small, and some patient medical histories were limited. But, according to the present study, the variation is high and potential differences are small. Therefore, prospective studies to determine those potential small differences must be very large. 
1 Alkalay AL, Graham JM Jr, Pomerance JJ: Evaluation of neonates born with intrauterine growth retardation: review and practice guidelines. J Perinatol 1998;18:142-151.

2 Lee PA, Chernausek SD, Hokken-Koelega AC, Czernichow P; International Small for Gestational Age Advisory Board: International Small for Gestational Age Advisory Board consensus development conference statement: management of short children born small for gestational age, April 24October 1, 2001. Pediatrics 2003;111:12531261.

3 Clayton PE, Cianfarani S, Czernichow P, Johannsson G, Rapaport R, Rogol A: Management of the child born small for gestational age through to adulthood: a consensus statement of the International Societies of Pediatric Endocrinology and the Growth Hormone Research Society. J Clin Endocrinol Metab 2007;92:804-810.

4 Gardosi J: New definition of small for gestational age based on fetal growth potential. Horm Res 2006;65(suppl 3):15-18.

5 Karlberg J, Albertsson-Wikland K: Growth in full-term small-for-gestational-age infants: from birth to final height. Pediatr Res 1995;38:733-739. Erratum in: Pediatr Res 1996;39:175.

6 Hokken-Koelega AC, De Ridder MA, Lemmen RJ, Den Hartog H, De Muinck KeizerSchrama SM, Drop SL: Children born small for gestational age: do they catch up? Pediatr Res 1995;38:267-271.

7 Wit JM, Finken MJ, Rijken M, de Zegher F: Preterm growth restraint: a paradigm that unifies intrauterine growth retardation and preterm extra-uterine growth retardation and has implications for the small-for-gestational-age indication in growth hormone therapy. Pediatrics 2006;117:e793-e795.

8 de Zegher F, Albertsson-Wikland K, Wollmann HA, Chatelain P, Chaussain JL, Löfström A, Jonsson B, Rosenfeld RG: Growth hormone treatment of short children born small for gestational age: growth responses with continuous and discontinuous regimens over 6 years. J Clin Endocrinol Metab 2000;85:2816-2821.

9 Van Pareren Y, Mulder P, Houdijk M, Jansen M, Reeser M, Hokken-Koelega A: Adult height after long-term, continuous growth hormone (GH) treatment in short children born small for gestational age: results of a randomized, double-blind, dose-response GH trial. J Clin Endocrinol Metab 2003;88: 3584-3590.

10 Cutfield WS, Reiter EO, on behalf of the KIGS International Board: Growth and growth hormone treatment in children born small for gestational age and with SilverRussell syndrome; in Ranke MB, Price DA, Reiter EO (eds): Growth Hormone Therapy in Pediatrics - 20 Years of KIGS. Basel, Karger, 2007, pp 389-399.
11 Tauber M, Ester W, Auriol F, Molinas C, Fauvel J, Caliebe J, Nugent T, Fryklund L, Ranke MB, Savage MO, Clark AJ, Johnston LB, Hokken-Koelega AC; NESTEGG Group: GH responsiveness in a large multinational cohort of SGA children with short stature (NESTEGG) is related to the exon 3 GHR polymorphism. Clin Endocrinol (Oxf) 2007; 67:457-461.

12 Saenger P, Czernichow P, Hughes I, Reiter EO: Small for gestational age: short stature and beyond. Endocr Rev 2007;28:219-251.

13 Naeye RL, Blanc W, Paul C: Effects of maternal nutrition on the human fetus. Pediatrics 1973;52:494-503.

14 Teasdale F: Idiopathic intrauterine growth retardation: histomorphometry of the human placenta. Placenta 1984;5:83-92.

15 Pringle PJ, Geary MP, Rodeck CH, Kingdom JC, Kayamba-Kay's S, Hindmarsh PC: The influence of cigarette smoking on antenatal growth, birth size, and the insulin-like growth factor axis. J Clin Endocrinol Metab 2005;90:2556-2562.

16 Dunger DB: KIGS 20 years: children born small for gestational age; in Ranke MB, Price DA, Reiter EO (eds): Growth Hormone Therapy in Pediatrics - 20 Years of KIGS. Basel, Karger, 2007, pp 400-406.

17 Li M, Squire JA, Weksberg R: Molecular genetics of Wiedemann-Beckwith syndrome. Am J Med Genet 1998 2;79:253-259.

18 Constância M, Kelsey G, Reik W: Resourceful imprinting. Nature 2004;432:53-57.

19 Eggermann T, Schönherr N, Eggermann K, Buiting K, Ranke MB, Wollmann HA, Binder G: Use of multiplex ligation-dependent probe amplification increases the detection rate for $11 \mathrm{p} 15$ epigenetic alterations in SilverRussell syndrome. Clin Genet 2008;73:7984.

20 Gicquel C, Rossignol S, Cabrol S, Houang M, Steunou V, Barbu V, Danton F, Thibaud N, Le Merrer M, Burglen L, Bertrand AM, Netchine I, Le Bouc Y: Epimutation of the telomeric imprinting center region on chromosome 11p15 in Silver-Russell syndrome. Nat Genet 2005;37:1003-1007.

21 Wollmann HA, Kirchner T, Enders $H$, Preece MA, Ranke MB: Growth and symptoms in Silver-Russell syndrome: review on the basis of 386 patients. Eur J Pediatr 1995; 154:958-968.

22 Price SM, Stanhope R, Garrett C, Preece MA, Trembath RC: The spectrum of SilverRussell syndrome: a clinical and molecular genetic study and new diagnostic criteria. J Med Genet 1999;36:837-842.
23 Ranke MB, Lindberg A, Cowell CT, Wikland KA, Reiter EO, Wilton P, Price DA; KIGS International Board: Prediction of response to growth hormone treatment in short children born small for gestational age: analysis of data from KIGS (Pharmacia International Growth Database). J Clin Endocrinol Metab 2003;88:125-131.

24 de Ridder MA, Stijnen T, Hokken-Koelega AC: Prediction model for adult height of small for gestational age children at the start of growth hormone treatment. J Clin Endocrinol Metab 2008;93:477-483.

25 Brückener A, Jordan M: A Multicentre Trial Evaluating the Efficacy and Safety of Genotropin ${ }^{\circledR}$ in Children Short for Gestational Age. Final Report of the Trial CTN 93-8122003-DE00. Erlangen, Pharmacia \& Upjohn, 2000, pp 1-41.

26 Brandt I, Reinken L: The growth rate of healthy children in the first 16 years: BonnDortmund longitudinal developmental study. Klin Pädiatr 1988;200:451-456.

27 Ester W, Bannink E, van Dijk M, Willemsen $\mathrm{R}$, van der Kaay D, de Ridder M, HokkenKoelega A: Subclassification of small for gestational age children with persistent short stature: growth patterns and response to $\mathrm{GH}$ treatment. Horm Res 2008;69:89-98.

28 de Graaff LC, Meyer S, Els C, Hokken-Koelega $\mathrm{AC}: \mathrm{GH}$ receptor $\mathrm{d} 3$ polymorphism in Dutch patients with MPHD and IGHD born small or appropriate for gestational age. Clin Endocrinol (Oxf.) 2008;68:930-934.

29 Carrascosa A, Audí L, Esteban C, Fernández-Cancio M, Andaluz P, Gussinyé M, Clemente M, Yeste D, Albisu MA: Growth hormone $(\mathrm{GH})$ dose, but not exon 3-deleted/ full-length GH receptor polymorphism genotypes, influences growth response to twoyear GH therapy in short small-for-gestational-age children. J Clin Endocrinol Metab 2008;93:147-153.

30 Ranke MB, Lindberg A: Growth hormone treatment of short children born small for gestational age or with Silver-Russell syndrome: results from KIGS (Kabi International Growth Study), including the first report on final height. Acta Paediatr Suppl 1996; 417:18-26.

31 Price SM, Stanhope R, Garrett C, Preece MA, Trembath RC: The spectrum of SilverRussell syndrome: a clinical and molecular genetic study and new diagnostic criteria. J Med Genet 1999;36:837-842.

32 Eggermann T, Meyer E, Ranke MB, Holder M, Spranger S, Zerres K, Wollmann HA: Diagnostic proceeding in Silver-Russell syndrome. Mol Diagn 2005;9:205-209.

33 Schönherr N, Meyer E, Roos A, Schmidt A, Wollmann HA, Eggermann T: The centromeric 11 p15 imprinting centre is also involved in Silver-Russell syndrome. J Med Genet 2007;44:59-63. 
34 Kuehl KS, Loffredo CA, Ferencz C: Failure to diagnose congenital heart disease in infancy. Pediatrics 1999;103:743-747.

35 Tanner K, Sabrine N, Wren C: Cardiovascular malformations among preterm infants. Pediatrics 2005; 116:e833-e838.

36 Rosenthal GL, Wilson PD, Permutt T, Boughman JA, Ferencz C: Birth weight and cardiovascular malformations: a population-based study. The Baltimore-Washington Infant Study. Am J Epidemiol 1991;133:1273-1281.

37 Kuehl KS, Loffredo CA: Genetic and environmental influences on malformations of the cardiac outflow tract. Expert Rev Cardiovasc Ther 2005;3:1125-1130.

38 Volpe P, Marasini M, Caruso G, Marzullo A, Buonadonna AL, Arciprete P, Di Paolo S, Volpe G, Gentile M: 22q11 deletions in fetuses with malformations of the outflow tracts or interruption of the aortic arch: impact of additional ultrasound signs. Prenat Diagn 2003;23:752-757.

39 Chen CP, Chern SR, Chang TY, Tzen CY, Lee CC, Chen WL, Lee MS, Wang W: Prenatal diagnosis of de novo terminal deletion of chromosome 7q. Prenat Diagn 2003;23:375379.
40 Horta BL, Victora CG, Menezes AM, Halpern R, Barros FC: Low birthweight, preterm births and intrauterine growth retardation in relation to maternal smoking. Paediatr Perinat Epidemiol 1997;11:140-151.

41 Hindmarsh PC, Geary MP, Rodeck CH, Kingdom JC, Cole TJ: Factors predicting ante- and postnatal growth. Pediatr Res 2008;63:99-102.

42 Dejmek J, Solansk y I, Podrazilová K, Srám $\mathrm{RJ}$ : The exposure of non-smoking and smoking mothers to environmental tobacco smoke during different gestational phases and fetal growth. Environ Health Perspect 2002;110:601-606

43 Ward C, Lewis S, Coleman T: Prevalence of maternal smoking and environmental tobacco smoke exposure during pregnancy and impact on birth weight: retrospective study using Millennium Cohort. BMC Public Health 2007;7:81.

44 Figueras F, Meler E, Eixarch E, Francis A, Coll O, Gratacos E, Gardosi J: Association of smoking during pregnancy and fetal growth restriction: subgroups of higher susceptibility. Eur J Obstet Gynecol Reprod Biol 2008; 138:171-175.
45 Bittencourt AL, Garcia AG: Pathogenesis and pathology of hematogenous infections of the fetus and newborn. Pediatr Pathol Mol Med 2002;21:353-399.

46 Kobayashi K, Tajima M, Toishi S, Fujimori K, Suzuki Y, Udagawa H: Fetal growth restriction associated with measles virus infection during pregnancy. J Perinat Med 2005;33: 67-68.

47 Bergström S: Infection-related morbidities in the mother, fetus and neonate. J Nutr 2003; 133:1656S-1660S.

48 Romero R, Gotsch F, Pineles B, Kusanovic JP: Inflammation in pregnancy: its roles in reproductive physiology, obstetrical complications, and fetal injury. Nutr Rev 2007;65: S194-S202.

49 Siqueira FM, Cota LO, Costa JE, Haddad JP, Lana AM, Costa FO: Intrauterine growth restriction, low birth weight, and preterm birth: adverse pregnancy outcomes and their association with maternal periodontitis. J Periodontol 2007;78:2266-2276.

50 Offenbacher S, Katz V, Fertik G, Collins J, Boyd D, Maynor G, McKaig R, Beck J: Periodontal infection as a possible risk factor for preterm low birth weight. J Periodontol 1996; 67(suppl):1103-1113 